\title{
Will Total Knee Replacement Ever Provide Normal Knee Function?
}

\author{
István Gergely, Tudor Sorin Pop, Tiberiu Bățagă, Andrei-Marian Feier, Sándor-György Zuh, \\ Octav Russu
}

University of Medicine and Pharmacy, Tîrgu Mureș, Romania

\section{CORRESPONDENCE}

\section{Andrei Marian-Feier \\ Str. Gheorghe Marinescu nr. 38 \\ 540139 Tîrgu Mureș, Romania \\ Tel: +40 747501392 \\ E-mail: andreifeier@gmx.com}

\section{ARTICLE HISTORY}

Received: April 26, 2017

Accepted: May 13, 2017
István Gergely • Str. Gheorghe Marinescu nr. 38 540139 Tîrgu Mureș, Romania. Tel: +40 265215551. E-mail: gergelyistvan@studium.ro

Tudor Sorin Pop • Str. Gheorghe Marinescu nr. 38, 540139 Tîrgu Mures, Romania. Tel: +40 265215551. E-mail: sorintpop@yahoo.com

Tiberiu Bățagă • Str. Gheorghe Marinescu nr. 38 540139 Tîrgu Mures, Romania. Tel: +40 265215551 E-mail: tbataga@gmail.com

Sándor-György Zuh • Str. Gheorghe Marinescu nr. 38, 540139 Tîrgu Mureș, Romania. Tel: +40 265215551. E-mail: zuh.sandor@gmail.com

Octav Russu • Str. Gheorghe Marinescu nr. 38 , 540139 Tîrgu Mures, Romania. Tel: +40 265215551. E-mail: octav@genunchi.ro

\begin{abstract}
Knee osteoarthritis or gonarthrosis is considered the most common joint disease, affecting more than $70 \%$ of subjects aged over 65 years. Its occurrence is increasing with age and is more problematic with the current rise in the incidence of obesity. In severe and advanced cases, total knee arthroplasty is recommended as a gold standard therapy for pain relief, restoration of normal knee function, and quality of life improvement. There are numerous controversies whether total knee arthroplasty is able to reach and provide end-point outcomes and restore previous function of the knee joint. Studies suggest that the surgeons' experience, type of prosthesis used, associated pathology, underlying pathologies, risk factors, continuous passive movement, and patient expectations about the surgery may influence the outcomes to a great extent. "Normal knee function" is a statement that is hardly defined in the current literature, as authors usually refer to subjective results when analyzing outcomes. Objective results may be more straightforward, but they do not always symbolize the actual state that the patient is reporting or the actual quality of life. Our objective was to analyze and present summaries of the current literature regarding normal knee function restoration after total knee replacement surgery. Our literature review results confirm the hypothesis that subjective and objective results are difficult to interpret and unravel. Complex future trials may bring supplementary and clearer conclusions regarding knee function and kinematics, clinical improvement, patient satisfaction, and quality of life.
\end{abstract}

Keywords: knee replacement, total knee arthroplasty, outcomes

\section{INTRODUCTION}

Osteoarthritis (OA) of the knee or gonarthrosis is the most common joint disease, its occurrence increasing with age. Its prevalence reaches $30 \%$ between 45-65 years and about $70 \%$ in subjects aged over 65 years. Disease distribution is identical for both genders under the age of 55 , but between $55-75$ years, women seem to have a higher incidence. ${ }^{1}$ Gonarthrosis is the consequence of a functional imbalance between the strength of the articular structures and the stresses, friction, and traumas exerted on them. When demands become amplified and go beyond the physiological threshold or normal stresses are exerted on a low-strength cartilage, the conditions for alterations in cartilage are created. ${ }^{2}$ Together with underlying biomechanical factors that may predispose subjects 
to knee OA, obesity, previous knee injuries, and intensive physical activities are considered key risk factors for the development and advancement of the disease and the necessity for total knee replacement. ${ }^{3-5}$ Total knee arthroplasty (TKA) is now considered the gold standard therapy in treating end-stage knee osteoarthritis, with a nearly $90 \%$ patient satisfaction rate reported in recent studies. ${ }^{6-12}$ Even with the high patient satisfaction rate reports, some studies also suggest that TKA is not achieving its primary goal of pain relief and improvement of joint function. ${ }^{13-15}$ The successfulness and outcome of a TKA mainly depends on the senior surgeon and his interaction with instruments, the operating team, and patient, his skill, learning curve, enthusiasm, and hospital facilities that are available. ${ }^{16}$ The surgeon's actions are considered to have the prime effect on outcomes: postoperative instability, malalignment, poor range of motion, sepsis, and other failure outcomes. Besides the surgeon's experience and managerial skills, rehabilitation and physiotherapy after the intervention is also essential in order to achieve the functional and clinical outcomes that are expected. ${ }^{17}$ Our review sought to highlight the outcomes reported in the literature after total knee replacement and to answer the question whether TKA restores the previous functionality of the affected joint.

\section{NORMAL CARTILAGE DESCRIPTION AND PATHOGENESIS OF KNEE OSTEOARTHRITIS}

The parts covered by cartilage in the knee joint are the femoral condyles, the tibial plateau, and the posterior surface of the patella. Thus, the articular movements are achieved by sliding between these three cartilage surfaces. ${ }^{18}$ The normal articular cartilage achieves two essential functions for locomotion: the transmission of mechanical forces to the bone extremitie,s and a smooth, perfectly congruent, self-lubricated surface. Usually, the cartilage is exposed to a continuous internal remodeling process, considered to be the result of the activity of chondrocytes and synovial cells. ${ }^{19}$ Cartilage cells show a low rate of division due to reduced DNA synthesis. ${ }^{19}$ Due to the hypocellularity of the articular cartilage, its mechanical and biochemical characteristics are dependent on the composition of extracellular matrix. ${ }^{19}$ Due to the increased concentration of proteoglycans, normal cartilage is poorly water-permeable. When a compressive force is applied, although the pressure in the cartilage increases immediately, it deforms slowly and reversibly, as the water surrounds the entire joint surface as a smooth film. When the force is removed, the layer of fluid on the surface of the cartilage is absorbed by proteogly- cans, which have a high density of negative charges. The capacity of proteoglycans to retain water and to increase in volume is limited by the tensioning collagen network. Hydrated proteoglycans are compressed into the meshes of the collagen network, creating considerable tissue pressure even in the absence of compressive forces. 1 The etiology of knee OA is usually described as intra-articular and extra-articular. Intra-articular causes produce a functional overload due to defective mechanical conditions such as traumas, meniscus and ligament lesions, quadriceps muscle atrophy, or König's disease. On the other hand, extraarticular factors include deviations in the frontal (genu valgum or varus) or sagittal planes (genu flexum). The existence of anatomical malformations favoring articular overload (genu varum, genu valgum, lateral instability of the spine) are recognized as "pre-arthritic malformations" because they favor and lead to OA over time.1 In addition to these causes, a number of factors contributing to overweight, prolonged kneeling professions, and sports (football, rugby, skiing) are also encountered in the etiology of the disease. OA may reach only a part or the entire knee joint, thus distinguishing the following locations according to knee anatomy: ${ }^{20}$

- internal tibio-femoral OA that concerns the inner compartment of the knee joint;

- external tibio-femoral OA that concerns the outer knee compartment;

- femoral-patellar OA involving the patello-femoral compartment of the knee;

- global OA of the knee joint.

\section{SHORT DESCRIPTION OF THE CONVENTIONAL TKA SURGICAL TECHNIQUE21}

There are several techniques described in orthopedics regarding TKA, which is performed under aseptic conditions, under spinal or general anesthesia, with the patient in dorsal decubitus and the knee to be operated in a $90^{\circ}$ flexion position. A tourniquet can be applied around the thigh to help surgical exposure and limit the blood loss, but this practice should be avoided in patients with a history of deep vein thrombosis.

The knee joint is approached anteriorly by a para-patellar medial incision; the osteophytes and the intra-articular soft tissue are afterwards removed. The bony excisions in the distal femur are perpendicular to the mechanical shaft using an intramedullary alignment system. In the proximal tibia, bone excisions are also perpendicular to the mechanical shaft, but both intramedullary or extramedul- 
lary alignment systems can be used. Restoring mechanical alignment is important to allow optimal distribution of the knee load and to prevent eccentric loading. Enough bone should be removed so that the prosthesis will re-create the level of the joint line. This allows the ligaments around the knee to be perfectly balanced and thus prevent possible alterations of the height of patella, which may have a damaging effect on femoral-patellar biomechanics.

Due to the preoperative deformation, some ligaments around the knee are contracted. These will be strained gradually to balance the soft tissues around the knee and allow optimal kinetic articulation. After the intercondylar space is prepared, the mobility of the new articulation (flexion, extension) with the test components is controlled, and the bone surfaces are washed. If the patellar-femoral joint is significantly affected, the patella surface may be restored with a polyethylene component. The initial width of the patella should be restored.

Once the final components have been selected, they are fixed with polymethyl methacrylate cement. If noncemented prostheses are used, they are set by the press-fit technique, and the bone growth around the prosthesis will ensure the fixation in the long term. The tourniquet should be removed before closing, and the knee joint is usually drained and fixed in full extension. At the end of the intervention, the pulse at the level of the dorsalis pedis artery is tested.

\section{OUTCOMES AFTER TOTAL KNEE ARTHROPLASTY - LITERATURE REVIEW}

With the implementation of modern prosthetics, the survival rates following TKA have increased radically to a $90 \%$ rate at 15 years after the surgery. ${ }^{22}$

\section{Patient satisfaction}

With increased survival rates, the patients' satisfaction, post-surgery joint performance and functionality have become an obligatory topic. Meeting patient expectations is of the highest significance in achieving patient fulfilment after primary TKA. ${ }^{9,12,23}$ It was demonstrated that patient expectations regarding surgery have a significant effect on the satisfaction rate after surgery, even if functionality was not completely restored. ${ }^{13}$ Robertsson et al. studied whether Swedish patients operated by knee arthroplasty are satisfied with the procedure or not. ${ }^{14}$ They ran a questionnaire on 27,372 subjects who underwent knee arthroplasty between 1981 and 1995 in the Swedish Knee Arthroplasty Register. Their follow-up range was between 2 and
17 years, and $92 \%$ of the individuals were satisfied with the outcomes of the procedure. However, a higher rate of satisfaction was reported in those who underwent TKA compared to unilateral compartment arthroplasty. In a similar observational study, Anderson et al. found that $88.8 \%$ of subjects were satisfied with the surgery, and $91 \%$ felt that they made the right decision when opting for total replacement. ${ }^{24}$ An important detail was that patients with higher satisfaction rates were also scoring better in the Western Ontario and McMaster University Osteoarthritis Index (WOMAC) evaluation ( $\mathrm{p}<0.05)$.

\section{Subjective outcomes}

In 108 patients who underwent TKA with an average of 4.9 years of follow-up, the WOMAC subjective score and patient satisfaction were studied. ${ }^{25}$ WOMAC was once again correlated with the self-reported satisfaction level. Seventy-three patients (68\%) were "very satisfied" with the surgery. In a study from 2009, Bourne et al. assessed patient satisfaction on subjects who underwent TKA. ${ }^{26}$ From 1,703 patients, 1375 (81\%) were satisfied with the overall procedure results. WOMAC is the most common tool used to evaluate subjective outcomes after treating osteoarthritis and includes questions regarding three main subscales considered as end-points: pain, stiffness, and physical function. ${ }^{27,28}$ The score usually ranges from 100 to 0 (from worse to best), but some authors reverse the score in their reports from 0 to 100 , a 100 score showing the best outcome possible. In Bourne's study, the reversed WOMAC score improved significantly to $81.9 \pm 16.6$ with an average overall change of $39.5 \pm 19.8$ at the one-year follow-up.26 In their report, the pain subscale had the highest change compared to the preoperative state $(86.2 \pm 16.3$, with a change of $42.9 \pm 20.6$ in 12 months).

\section{Surgical technique and prosthesis type influence the desired outcomes}

A common discussed topic in the orthopedics community is whether to use posterior stabilized arthroplasty or retain the posterior cruciate ligament (PCL) during surgery. It is a topic of debate, as several authors and systematic reviews provided evidence that sacrificing the PCL might lead to better functional outcomes and a reduced range of motion limitation..$^{29,30}$ Other authors concluded in 2008, using a sample of 100 patients, that the two techniques had shown no superiority to each other regarding pain, quality of life, and knee function two years post-surgery. ${ }^{31}$ Seon et al. dem- 
onstrated that posterior stabilized TKA is superior in terms of weight-bearing flexion, but with no superiority observed in the clinical outcomes. ${ }^{32}$ It is additionally considered that the type of prosthesis is influencing the results after TKA. In a meta-analysis comprising 130 studies, Callahan et al. analyzed reported outcomes after TKA with the following techniques: PCL-sacrificing TKA, PCL-retaining TKA, and PCL-substituting TKA. ${ }^{33}$ The mean range of motion was 99 degrees following a PCL-sacrificing TKA, 107 degrees after PCL-retaining knee arthroplasty, and 103 after PC-substituting TKA. They also concluded that underlying knee pathology and prosthesis type can be considered as predictors for outcomes following TKA. After analyzing data regarding postoperative flexion range of motion following 313 PCL sparing TKAs, Parsley et al. affirmed that subjects who had limited flexion preoperatively showed an increase in flexion after surgery. ${ }^{34}$ In comparison, individuals with above 105 degrees of flexion before surgery showed a decline in flexion after the surgery.

\section{Associated risk factors and underlying disease}

Associated disorders, underlying disease type or risk factors may influence the final outcome after knee replacement. Patients who underwent TKA with underlying rheumatoid arthritis, septic arthritis, or avascular necrosis had reduced flexion range of motion postoperatively $\left(100^{\circ}\right)$ compared to subjects with OA, trauma, or gout $\left(120^{\circ}\right)$ as a primary diagnosis. ${ }^{35}$ Studying the same topic, Harvey et al. concluded that patients who had OA as a primary diagnosis lost $2^{\circ}$ of flexion after TKA, and patients who had rheumatoid arthritis as underlying disease gained $5^{\circ}$ of flexion at a minimum 12 months follow-up. ${ }^{36}$

\section{Continuous passive motion - yes or no?}

Usage of continuous passive motion (CPM) is a frequent topic addressed in the rehabilitation process after TKA for obtaining better clinical and subjective results. One of the fundamental meta-analyses that addressed this topic was published in 2004 by Brosseau et al., which concluded that $\mathrm{CPM}$, in addition to physiotherapy, has statistically significant superior effects when analyzing active knee flexion and decreased hospitalization time compared to physiotherapy alone. ${ }^{37}$ However, CPM usage was not correlated with better passive knee flexion and passive or active knee extension. In a review elaborated for French clinical practice guidelines, CPM was found to provide beneficial effects regarding pain, swelling, and knee kinematics, together with a shorter recovery time post-surgery. ${ }^{38}$
However, a clear statement regarding long-term outcomes could not be elaborated due to short follow-up times in studies reporting CPM as rehabilitation procedure. Pope et al. reported beneficial postoperative outcomes and reduced joint manipulation, but only for a short time. ${ }^{39}$ At one week after TKA, there was a statistically significant increase in the range of flexion and total range of movement in the group that used CPM. At one year, however, they found no significant differences in mean flexion, range of motion, or functional results between the groups.

\section{CONCLUSIONS}

The review of the literature has many contradictions and controversies between the authors' opinions and the obtained results. Higher-evidence trials may bring further clear statements regarding knee function, clinical improvement, patient satisfaction, and quality of life. Will TKA ever be able to provide normal knee function? If we address normality as a patient subjective outcome and satisfaction after the surgery, we can state that TKA provides sufficient beneficial effects to restore normal knee function. If objective outcomes are assessed, the conclusion whether a knee is functioning normally is hard to be established among the literature's disagreements.

\section{CONFLICT OF INTEREST}

Nothing to declare.

\section{REFERENCES}

1. Pop TS. Elemente de ortopedie, Târgu Mureș: Univesity Press. 2005.

2. Archibeck MJ, Jacobs JJ, Roebuck KA, Glant TT. The basic science of periprosthetic osteolysis. Instr Course Lect. 2001;50:185-195.

3. Messier SP, Loeser RF, Mitchell MN, et al. Exercise and weight loss in obese older adults with knee osteoarthritis: a preliminary study. J Am Geriatr Soc. 2000;48:1062-1072.

4. Christensen R, Astrup A, Bliddal H. Weight loss: the treatment of choice for knee osteoarthritis? a randomized trial. Osteoarthritis Cartilage. 2005;13:20-27.

5. Cerejo R, Dunlop DD, Cahue S, et al. The influence of alignment on risk of knee osteoarthritis progression according to baseline stage of disease. Arthritis Rheum. 2002;46:2632-2636.

6. Dunbar MJ, Robertsson O, Ryd L, Lidgren L. Appropriate questionnaires for knee arthroplasty. Results of a survey of 3600 patients from the Swedish Knee Arthroplasty Registry. J Bone Joint Surg Br. 2001;83:339-344.

7. Hawker G, Wright J, Coyte P, Paul J, Dittus R, et al. Health-related quality of life after knee replacement. Results of the knee replacement patient outcomes research team study. J Bone Joint Surg Am. 1998;80:163-173.

8. Hawker G, Wright J, Coyte P, et al. Differences between men and women in the rate of use of hip and knee arthroplasty. $N$ Eng $\mathrm{J}$ Med. 2000;342:1016-1022

9. Heck DA, Robinson RL, Partridge CM, Lubitz RM, Freund DA. Patient outcomes after knee replacement. Clin Orthop Relat Res. 1998;356:93-110.

10. Bourne RB, McCalden RW, MacDonald SJ, Mokete L, Guerin J. Influence of patient factors on TKA outcomes at 5 to 11 years followup. Clin Orthop Relat Res. 2007;464:27-31. 
11. Burnett RS, Haydon CM, Rorabeck CH, Bourne RB. Patella resurfacing versus nonresurfacing in total knee arthroplasty: results of a randomized controlled clinical trial at a minimum of 10 years' followup. Clin Orthop Relat Res. 2004;428:12-25.

12. Chesworth BM, Mahomed NN, Bourne RB, Davis AM. Willingness to go through surgery again validated the WOMAC clinically important difference from THR/TKR surgery. J Clin Epidemiol. 2008;61:907-918.

13. Noble PC, Conditt MA, Cook KF, Mathis KB. The John Insall Award: Patient expectations affect satisfaction with total knee arthroplasty. Clin Orthop Relat Res. 2006;452:35-43.

14. Robertsson O, Dunbar M, Pehrsson T, Knutson K, Lidgren L. Patient satisfaction after knee arthroplasty: a report on 27,372 knees operated on between 1981 and 1995 in Sweden. Acta Orthopaedica Scandinavica. 2000;71:262-267.

15. Wylde V, Learmonth I, Potter A, Bettinson K, Lingard E. Patient- reported outcomes after fixed- versus mobile-bearing total knee replacement: a multi-centre randomised controlled trial using the Kinemax total knee replacement. J Bone Joint Surg Br. 2008;90:1172-1179.

16. Moreland JR. Mechanisms of failure in total knee arthroplasty. Clin Orthop Relat Res. 1988;226:49-64.

17. Deyle GD, Allison SC, Matekel RL, et al. Physical therapy treatment effectiveness for osteoarthritis of the knee: a randomized comparison of supervised clinical exercise and manual therapy procedures versus a home exercise program. Phys Ther. 2005;85:1301-1317.

18. Heijink A, Gomoll AH, Madry H, et al. Biomechanical considerations in the pathogenesis of osteoarthritis of the knee. Knee Surg Sports Traumatol Arthrosc. 2012;20:423-435.

19. Fabi DW, Mohan V, Goldstein WM, Dunn JH, Murphy BP. Unilateral vs Bilateral Total Knee Arthroplasty Risk Factors Increasing Morbidity. J Arthroplasty. 2011;26:668-673.

20. Luyten FP, Denti M, Filardo G, Kon E, Engebretsen L. Definition and classification of early osteoarthritis of the knee. Knee Surg Sports Traumatol Arthrosc. 2012;20:401-406.

21. Palmer S. Total Knee Arthroplasty. Available at: http://emedicine. medscape.com/article/1250275-overview

22. Gill Gs. Joshi AB. Long-term results of cemented, posterior cruciate ligament-retaining total knee arthroplasty in osteoarthritis. Am J Knee Surg. 2001;14:209-214.

23. Janse AJ, Gemke RJ, Uiterwaal CS, van der Tweel I, Kimpen JL, Sinnema G. Quality of life: patients and doctors don't always agree: a meta-analysis. J Clin Epidemiol. 2004;57:653-661.

24. Anderson JG, Wixson RL, Tsai D, Stulberg SD, Chang RW. Functional outcome and patient satisfaction in total knee patients over the age of 75 J Arthroplasty. 1996;11:831-840.

25. Bullens PH, van Loon CJ, de Waal Malefijt MC, Laan RF, Veth RP. Patient satisfaction after total knee arthroplasty: a comparison between subjective and objective outcome assessments. J Arthroplasty. 2001;16:740-747.

26. Bourne RB, Chesworth BM, Davis AM, Mahomed NN, Charron KD. Patient satisfaction after total knee arthroplasty: who is satisfied and who is not? Clin Orthop Relat Res. 2010;468:57-63.
27. Bellamy N, Lybrand SG, Gee T. (2002) An evaluation of the convergence between three different methods of response status assignment (RSA) based on the WOMAC Osteoarthritis Index. Proceedings of the 66th Annual Scientific Meeting of the American College of Rheumatology, 2002.

28. Bellamy N, Buchanan WW, Goldsmith CH, Campbell J, Stitt LW. Validation study of WOMAC: a health status instrument for measuring clinically important patient relevant outcomes to antirheumatic drug therapy in patients with osteoarthritis of the hip or knee. J Rheumatol. 1988;15:18331840.

29. Jacobs WC, Clement DJ, Wymenga AB. Retention versus removal of the posterior cruciate ligament in total knee replacement: a systematic literature review within the Cochrane framework. Acta Orthop. 2005;76:757-768.

30. Harato K, Bourne RB, Victor J, Snyder M, Hart J, Ries MD. Midterm comparison of posterior cruciate-retaining versus -substituting total knee arthroplasty using the genesis ii prosthesis. A multicenter prospective randomized clinical trial. The Knee. 2008;15:217-221.

31. Chaudhary R, Beaupré LA, Johnston DW. Knee range of motion during the first two years after use of posterior cruciate-stabilizing or posterior cruciate-retaining total knee prostheses. A randomized clinical trial. J Bone Joint Surg Am. 2008;90:2579-2586.

32. Seon JK, Park JK, Shin YJ, Seo HY, Lee KB, Song EK. Comparisons of kinematics and range of motion in high-flexion total knee arthroplasty: Cruciate retaining vs. Substituting designs. Knee Surg Sport $\operatorname{Tr} A$. 2011;19:2016-2022.

33. Callahan CM, Drake BG, Heck DA, Dittus RS. Patient outcomes following tricompartmental total knee replacement. A meta-analysis. JAMA. 1994:271:1349-1357.

34. Parsley BS, Engh GA, Dwyer KA. Preoperative flexion. Does it influence postoperative flexion after posterior-cruciate-retaining total knee arthroplasty? Clin Orthop Relat Res. 1992;275:204-210.

35. Schurman DJ, Matityahu A, Goodman SB, et al. Prediction of postoperative knee flexion in Insall-Burstein II total knee arthroplasty. Clin Orthop. 1998:353:175-184.

36. Harvey IA, Barry K, Kirby SP, Johnson R, Elloy MA. Factors affecting the range of movement of total knee arthroplasty. J Bone Joint Surg Br. 1993;75:950-955

37. Brosseau L, Milne S, Wells G, et al. Efficacy of continuous passive motion following total knee arthroplasty: a metaanalysis. J Rheumatol. 2004:31:2251-2264.

38. Postel JM, Thoumie P, Missaoui B, et al. Continuous passive motion compared with intermittent mobilization after total knee arthroplasty. Elaboration of French clinical practice guidelines. Ann Readapt Med Phys. 2007; 50:244-257.

39. Pope R, Corcoran S, McCaul K, Howie DW. Continuous passive motion after primary total knee arthroplasty. Does it offer any benefits? Journal of Rehabilitation Research \& Development. 2000;37:179-188. 